\title{
THE IMPACT OF CHARLSON'S COMORBIDITY INDEX IN OVERALL SURVIVAL FOR ADVANCED EPITHELIAL OVARIAN Câncer
}

A.C.Camargo

Cancer Center

www.accamargo.org.br
Rafael Leite Nunes ${ }^{1 *}$, Henrique Mantoan ${ }^{1}$, Bruna Tirapelli Gonçalves ${ }^{1}$, Lillian Yuri Kumagai ${ }^{1}$, Levon BadiglianFilho $^{1}$, Carlos Chaves Faloppa1, Louise de Brot ${ }^{2}$, Alexandre Andre B. A. Costa ${ }^{3}$ and Glauco Baiocchi ${ }^{*}$

${ }^{1}$ Department of Gynecologic Oncology, AC Camargo Cancer Center; ${ }^{2}$ Department of Pathology, AC Camargo Cancer Center, ${ }^{3}$ Department of Medical Oncology, AC Camargo Cancer Center

R. Prof. Antonio Prudente, 211, Liberdade - São Paulo, SP - BRAZILｅ-mail: *glauco.baiocchi@accamargo.org.br

\section{INTRODUCTION}

Nearly $70 \%$ of cases have advanced disease (stage III or IV) at diagnosis, the cornerstone treatment of which is cytoreductive surgery, because residual disease after initial surgery is one of the most important prognostic factors for survival. Although the value of cytoreductive surgery is well established, the ideal time for primary treatment is unknown.

For patients not suitable for optimal cytoreduction because of disease extension or comorbidities, neoadjuvant chemotherapy with interval cytoreduction is preferred. However, cytoreductive surgery may require multivisceral resections, resulting in the potential risk of considerable postoperative morbidity and mortality. Therefore, preoperative screening to identify patients who might not be fit enough to undergo the surgical effort necessary to completely resect all tumors is needed

Our aim was to evaluate the impact of Charlson's Comorbidity Index $(\mathrm{CCl})$ in overall survival of advanced epithelial ovarian cancer.

\section{METHODS}

We retrospectively analyzed 82 patients with advanced epithelial ovarian cancer (Stages IIIA-IV) from 2009 to 2015. Clinical and pathological variables were extracted from medical-records. Patients were categorized according to $\mathrm{CCl}$ in 3 groups: low (0-1), intermediate (2-3) and high ( $\geq 4)$.
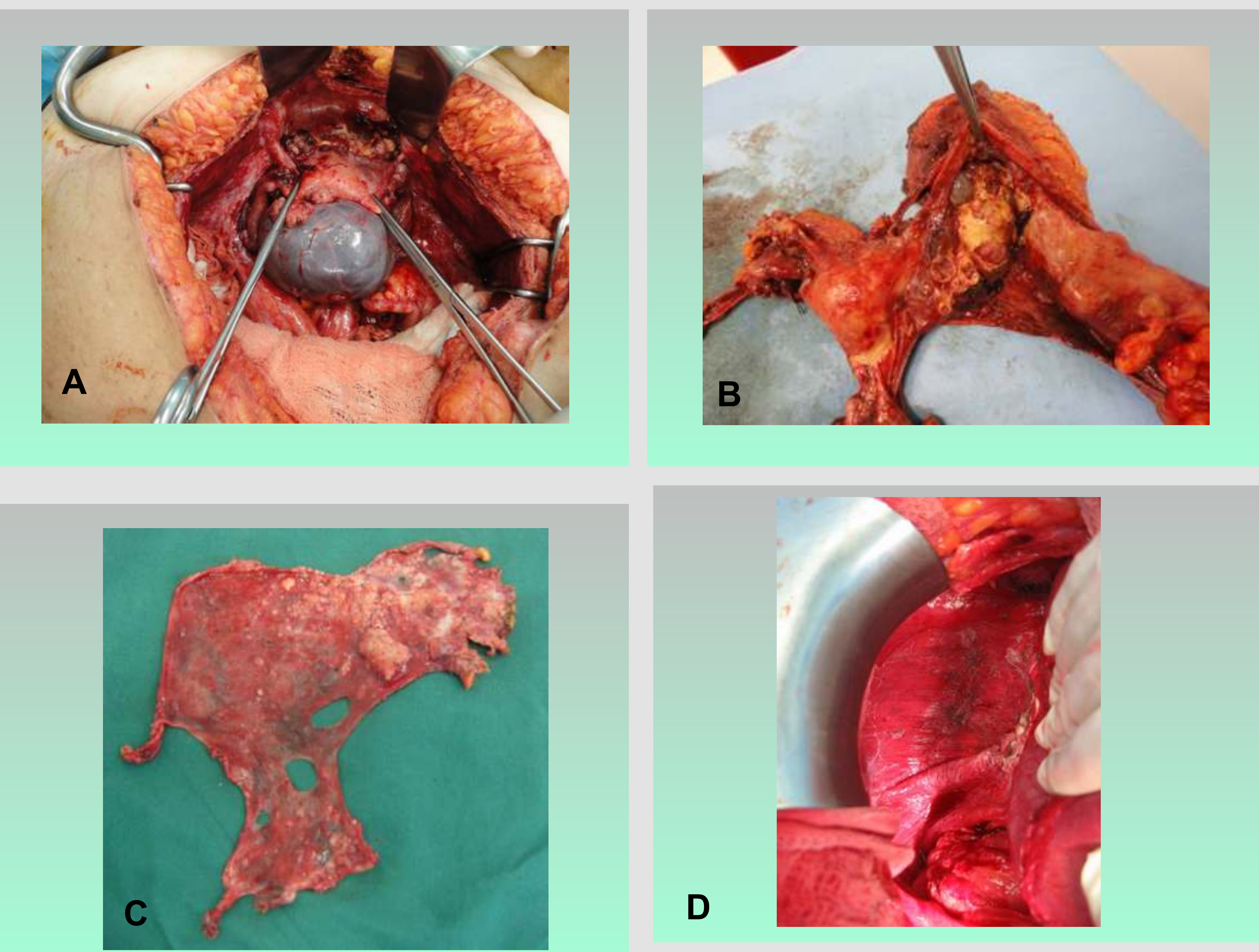

Figure 1. Example a patient submitted to optimal primary cytoreduction for a stage IIIC epithelial adenocarcinoma. A. Pelvic aspect of pelvic disease. B. Surgical specimen of posterior modified pelvic exenteration. C. Right diaphragmatic peritonium. D. Aspect of right diaphragm after peritonial resection.

\section{RESULTS}

The median age was 57 years and 62(78.5\%) were high-grade serous tumors. Forty-five (54.9\%) cases had primary cytoreductive surgery, 33(40.2\%) interval cytoreduction and 4(4.9\%) staging surgery. Five (6\%) patients had stages IIIA-IIIB tumors, 64(78\%) stage IIIC and 13(15.8\%) stage IV. Sixty-one $(75.3 \%)$ cases had no residual disease after cytoreduction and $10(12.3 \%)$ residual disease $\leq 1 \mathrm{~cm}$.

The median Surgical Complexity Score (SCS) was $6(0-15)$ and 11 cases $(14.7 \%)$ had major complications ( $\mathrm{NCl}$ grade $\geq 3$ ), including $3(3.6 \%)$ deaths within 30 days after surgery. The $\mathrm{CCl}$ were low, intermediate and high in 38(46.9\%), $36(44.4 \%)$ and $7(8.6 \%)$ cases, respectively. Notably, $\mathrm{CCl}$ was not related to major complications $(p=0.3)$. The median OS and PFS were 70.5 and 20.2 months.

The median OS for patients with low, intermediate and high CCls were 91.8, 51.6 and 38.9 months, respectively $(p=0.11)$. However, $\mathrm{CCl}$ impacted PFS, as median PFS for patients with low, intermediate and high CCls were 32.1, 16.2 and 13.4 months, respectively $(p=0.004)$. Moreover, major complications negatively impacted OS compared to minor complications (91.8 vs.22.1; $p=0.002$ ), but not PFS (20.2 vs.22.2; $p=0.71)$.

\section{CONCLUSION}

Our data suggest that higher $\mathrm{CCl}$ negatively impacted PFS in advanced ovarian cancer.

\section{REFERENCES}

1. Bristow RE, Puri I, Chi DS. Cytoreductive surgery for recurrent ovarian cancer: a metaanalysis. Gynecol Oncol. 2009 Jan;112(1):265-74.

2. da Costa AA, Valadares CV, Mantoan $\mathrm{H}$, et al. The Value of Secondary Cytoreductive Surgery in Recurrent Ovarian Cancer and Application of a Prognostic Score. Int J Gynecol Cancer. 2016;26(3):449-55.

3. Kahl A, du Bois A, Harter P, Prader S, Schneider S, Heitz F, Traut A, Alesina PF, Meier B, Walz M, Brueckner A, Groeben HT, Brunkhorst V, Heikaus S, Ataseven B. Prognostic Value of the Age-Adjusted Charlson Comorbidity Index (ACCl) on Short- and Long-Term Outcome in Patients with Advanced Primary Epithelial Ovarian Cancer. Ann Surg Oncol. 2017 Nov; 24(12):3692-3699. 